\title{
Quem tem medo de Virginia Woolf?: psicopatologia, tempo e criatividade em
}

\author{
Mrs. Dalloway
}

\section{Who's afraid Virginia Woolf?: psychopathology, time and creativity in Mrs. Dalloway}

\author{
Táki AthanÁssios Cordás' 1 , Renato Luiz Marchetti ${ }^{2}$ \\ 1 Departamento de Psiquiatria da Universidade de São Paulo (USP), Instituto de Psiquiatria (IPq) do Hospital das Clínicas da Faculdade de Medicina da Universidade de São Paulo (HCFMUSP), \\ Programa de Transtornos Alimentares (AMBULIM) do IPq-HCFMUSP. \\ 2FMUSP, Ambulatórios do IPq-HCFMUSP, Projeto de Epilepsia e Psiquiatria (PROJEPSI) do Programa de Neuropsiquiatria do IPq-HCFMUSP.
}

Recebido: 24/6/2010 - Aceito: 18/5/2011

\begin{abstract}
Resumo
Contexto: Há um crescente interesse na relação entre transtornos psiquiátricos, particularmente transtorno bipolar do humor e criatividade. Objetivos: Explorar a presença de aspectos ligados à vida pessoal e à história médica da autora inglesa Virginia Woolf, portadora de um transtorno do humor bipolar grave, em sua obra literária. Métodos: Foi utilizado como objeto de pesquisa um de seus livros mais importantes, Miss Dalloway, frequentemente citado como paradigmático do romance moderno. Resultados: A exploração de conceitos como a vivência do tempo e aspectos de suas experiências delirantes durante as fases da doença são descritos e analisados dentro de contexto psicopatológico. Conclusão: $\mathrm{O}$ brilhantismo artístico do uso de experiências pessoais vividas durante períodos de sua doença em Miss Dalloway não apenas enaltece a obra de Virginia Woolf, como abre interessante exemplo para o estudo da relação arte-doença mental, ainda pouco explorado na obra da autora.
\end{abstract}

Cordás TA, Marchetti RL / Rev Psiq Clín. 2011;38(6):261-4

Palavras-chave: Romance, modernidade, pós-modernidade, criatividade, transtorno bipolar.

\begin{abstract}
Background: There is a growing interest in the relationship between mental illness, mainly bipolar disorder and creativity. Objectives: To explore the presence of aspects linked to the personal life and medical history in the literary works written by English writer Virginia Woolf, who suffered from bipolar disorder. Methods: One of her most important books, Miss Dalloway, was used as a means of research. This book is often cited as paradigmatic of the modern novel. Results: The exploration of concepts such as inner time and aspects of delusion periods of the illness are described and analyzed in the context of psychopathology. Discussion: The artistic brilliance of using personal experiences during periods of her illness in Miss Dalloway not only praises the work of Virginia Woolf, as it opens an interesting example to study the relationship between art, mental illness, yet little explored in the work of the author.
\end{abstract}

Cordás TA, Marchetti RL / Rev Psiq Clín. 2011;38(6):261-4

Keywords: Novel, modernity, post modernity, creativity, bipolar disorder.

\section{Introdução}

Adeline Virginia Woolf (1882-1941), nascida Virginia Bell, embora nunca tenha se autodenominado uma escritora moderna, é, junto com Joyce (Ulisses), Proust (Em busca do tempo perdido), Kafka (Metamorfose; O processo), Faulkner (O som e a fúria) e Alfred Döblin (Berlim Alexander Platz), um dos mais representativos autores da chamada modernidade estética (aproximadamente 1890-1930)․․

Crítica literária, ativista política, contista, biógrafa, Virginia foi uma das líderes do famoso grupo de Bloomsbury, que incluía o grande economista J. Maynard Keynes, os escritores E. M. Forster, Lytton Strachey, os pintores Vanessa Bell (irmã de Virginia) e Duncan Grant, o filósofo Bertrand Russel, Desmond MacCarthy - o melhor crítico dramático da sua geração -, entre outros. O chamado grupo de Bloomsbury se tornou um elemento decisivo na vida cultural inglesa da primeira metade do século passado, discutindo e divulgando temas como o feminismo, o socialismo e as teorias freudianas ${ }^{2}$.

Virginia e seu marido, Leonard Woolf, publicaram pela Hogarth Press (1917-1938), sua própria editora, notáveis autores como T. S. Eliot, Katherine Mansfield, E. M. Forster, Rilke, Máximo Gorki e, a partir de 1924, os 24 volumes da edição inglesa de Sigmund Freud2,3.

Virginia teve, aos 13 anos de idade, seu primeiro episódio do transtorno bipolar, que durou aproximadamente seis meses.
Seguiram-se vários episódios maníaco-depressivos psicóticos $(1897,1904,1910,1912,1915,1936,1941)$, além de quadros interfásicos e pelo menos duas tentativas de suicídio. Em seu diário, recordava-se de um deles como uma "pulsação desenfreada, com um sentimento de grande excitação incontrolável, seguindo-se um estado da mais profunda depressão e autoacusação"4.

Quando em elação, Leonard descreve que a fala de Virginia era incessante, o conteúdo paulatinamente tornava-se incoerente e já no dia seguinte ela piorava muito, a ponto de ter de ser segurada pelas suas enfermeiras (Virginia tinha quatro). Da mesma forma, descreve que, quando Virginia se apresentava em depressão, negava estar doente e se dizia culpada por tudo que ocorria ${ }^{5}$.

Em 28 de março de 1941, escreveu duas cartas de despedida para o marido e sua irmã Vanessa, dizendo-se prestes a enlouquecer novamente e, temendo o paulatino retorno das alucinações auditivas, encheu os bolsos com pesadas pedras e afogou-se no rio Ouse, perto de Sussex. Para Leonard, dizia:

"Queridíssimo, tenho certeza de que estou ficando louca outra vez: sinto que não podemos passar por mais uma dessas terríveis temporadas e desta vez eu não vou me recuperar. Começo a ouvir vozes e não consigo me concentrar. Por isso estou fazendo o que parece ser o melhor a fazer. Você me deu toda a felicidade que eu poderia ter. 
Você tem sido, sob todos os aspectos, tudo o que alguém poderia ser. Não creio que pudesse haver no mundo duas pessoas mais felizes, até que veio esta doença terrível. Não posso mais combatê-la, sei que estou estragando sua vida, que sem mim você poderia trabalhar. $\mathrm{E}$ vai, eu sei. Você vê que nem estou conseguindo escrever isso direito. Eu não consigo ler. O que eu quero dizer é que devo toda a felicidade que tive na vida a você. Você foi imensamente paciente comigo e tremendamente bom. Eu quero dizer isso e todo mundo sabe. Se alguém pudesse ter me salvado, esse alguém teria sido você. Tudo o que eu tinha se foi, exceto a certeza da sua bondade. Eu não posso continuar estragando sua vida. Não mais. Não creio que duas pessoas poderiam ter sido mais felizes do que nós fomos."6

\section{Metodologia}

Foi utilizado como objeto de pesquisa um de seus livros mais importantes, Miss Dalloway, frequentemente citado como paradigmático do romance moderno.

\section{Resultados}

"Mrs. Dalloway disse que ela própria iria comprar as flores."7

Assim começa, em tradução de Mário Quintana, Mrs. Dalloway, publicado em 1925 e, segundo a opinião de muitos críticos, seu livro mais notável e que iniciou sua sequência de obras definitivas pelos próximos 16 anos de sua vida: O farol (1927), As ondas (1931), Os anos (1937) e Entre os atos (publicado postumamente em 1941) ${ }^{8}$. Tão importante, que Virginia era muitas vezes referida como Mrs. Dalloway por membros de sua família, segundo entrevista recente de Virginia Nicholson, sobrinha-neta da autora, ao jornal espanhol El Pais ${ }^{9}$.

Tudo se passa num único dia enquanto Clarissa Dalloway, que já estivera presente em um conto anterior (Mrs. Dalloway em Bond Street), prepara uma recepção em sua casa para a mais frívola aristocracia britânica.

Esse é um romance moderno, diferente dos esquemas vitorianos predominantes, não sendo possível concebê-lo dentro dos cânones da época como um romance romântico, épico, de horror etc. Em cada ocasião em que é lido, algo diferente pode ser captado. Aqui se tentará fazer uma introdução a apenas três aspectos que podem ser destacados em Mrs. Dalloway: o papel da mulher, a vivência do tempo e os reflexos da própria doença de Virginia.

Clarissa Dalloway é o exato retrato da sociedade patriarcal e conservadora da época, a qual Virginia reiteradamente critica de maneira cáustica ${ }^{10}$. Questões básicas humanas como a reavaliação de escolhas do passado estão todo o tempo assombrando Clarissa, que abdicou do amor por uma vida social e economicamente segura, casando-se com um político tradicional. Feminista avant la lettre, um de seus mais famosos textos é Shakespeare's sister, incluído em A room of one's own. Nesse trabalho, a autora conjectura o que teria acontecido se Shakespeare tivesse uma irmã tão talentosa quanto ele? Judith não poderia estudar como o irmão e precisaria ler escondida dos pais, teria de cerzir meias, cuidar do guisado e casar jovem. Aos 17 anos fugiria de casa para Londres, onde tentaria expressar sua criatividade. Ridicularizada por querer representar no teatro, acabaria tendo um filho de um amante que a abandonaria... "matou-se em noite de inverno, e está enterrada em alguma encruzilhada onde agora param os ônibus em frente ao Elephant and Castle"10.

A vivência do tempo é um dos principais aspectos do romance. O historiador Lewis Mumford, em seu mais famoso livro acerca do papel das máquinas e da tecnologia sobre nossa rotina diária, fala do que ocorreu após a invenção do relógio mecânico pelos monges na Idade Média: “o relógio é uma peça de maquinário cujo 'produto' são os segundos e minutos... dissociou o tempo dos eventos humanos, criando a fantasia de um mundo independente e de sequências matematicamente medidas"11.

Aparentemente pouco acontece em Mrs. Dalloway; o dia marcado pelas batidas do Big Ben é um dia objetivamente comum, quase enfadonho. O leitor começa a perguntar-se onde está a história? Onde está o enredo? Mas internamente, o "tempo anímico e psicológico" (Santo Agostinho ${ }^{12}$ ) dos personagens é intenso, o curso do tempo distancia-se do objetivo e se relaciona com as vivências, o presente e o passado misturam-se continuamente. As ações externas, o enredo, não têm de fato nenhuma importância.

Embora Leonardo Woolf afirme que Virginia não lera Bergson e que nem conhecia sua filosofia ou sua doutrina do tempo por outra fonte, a afirmação soa estranha, na medida em que sua cunhada Karin Stephen era uma estudiosa e publicou um livro sobre o filósofo francês ${ }^{13}$.

Diferentes críticos literários franceses, já poucos anos após a publicação de Mrs. Dalloway, faziam a aproximação entre as ideias bergsonianas de "durée reelle" (tempo interior vivido) e sua contraposição ao tempo exterior, o tempo do relógio, e a forma de tratar o tempo no romance. Acredita-se hoje firmemente numa importante influência de Bergson na forma de lidar com temas como o tempo, a memória e a intuição nas obras de Virginia ${ }^{13}$.

A questão do tempo e de sua vivência são há muito tempo de grande interesse psicopatológico ${ }^{14}$. No seu livro Psicopatologia geral, Karl Jaspers aborda a vivência do tempo no capítulo sobre fenômenos subjetivos da vida psíquica mórbida, por meio do método fenomenológico. Nesse capítulo, Jaspers discorre sobre a estrutura básica da consciência, dentro da qual são vivenciados os diferentes fenômenos, objetos que se apresentam ao sujeito, como percepções, estados emocionais, desejos e outros. Os fenômenos são vivenciados dentro de um contexto global constituído por vivência de espaço e tempo, consciência corpórea e de realidade ${ }^{15}$.

Ao abordar a vivência do tempo, Jaspers esclarece, de maneira preliminar, a diferença entre três aspectos psicológicos básicos: a capacidade de avaliar e quantificar corretamente um intervalo de tempo, objeto de estudo da psicologia dos rendimentos; o manejo do tempo, por meio do qual decisões são tomadas em função dos significados do tempo atual, passado e futuro no contexto de uma vida, objeto de estudo da psicologia dos significados; e, finalmente, a vivência do tempo, em que os aspectos qualitativos e subjetivos do tempo são experimentados ${ }^{15}$. De nossa parte, gostaríamos de acrescentar que consideramos que o manejo do tempo, além dos aspectos significativos levantados por Jaspers, envolve também a capacidade de sequenciar as ações, o adiamento de impulsos e a tomada de decisões no tempo certo, as assim chamadas funções executivas, também objeto de estudo da psicologia dos rendimentos.

Os aspectos fenomenológicos básicos da vivência do tempo são a consciência momentânea da passagem do tempo, a consciência de duração de eventos passados imediatos, a consciência do presente em relação ao passado e ao futuro e a consciência do futuro. A consciência momentânea do tempo, de acordo com o método fenomenológico de Jaspers, corresponde à ideia de "durée reelle", de Bergson ${ }^{16}$. Compreendemos de maneira imediata quando alguém nos diz que o tempo demora a passar, num dia triste e enfadonho. Tal como outras propriedades primárias das vivências, como a cor de um objeto, ou o cheiro de uma flor, a passagem do tempo pode apenas ser descrita de maneira metafórica, o que torna especialmente vivas as descrições dos grandes artistas, como Virginia Woolf ${ }^{17}$.

Há ainda aspectos reflexivos que envolvem a vivência do tempo, quando o homem, ao pensar sobre o tempo, desenvolve conceitos filosóficos (no Ser e tempo, de Martin Heidegger; a ideia de "durée reelle" de Bergson), artísticos (na música Oração ao tempo, de Caetano Veloso; na poesia Ah! Os relógios, de Mário Quintana; o conceito de momento decisivo, na fotografia de Henri Cartier-Bresson), religiosos (no demiurgo de Platão; no deus eterno dos cristãos), físicos e matemáticos (no conceito de espaço-tempo, de contração e expansão do tempo da teoria da relatividade geral de Einstein), que aqui são chamados de consciência reflexiva do tempo. Bergson e as suas ideias, que foram bastante populares e influenciaram a maneira como muitos conceberam o tempo, possivelmente se incluindo aí Virginia Woolf, demonstram o poder cultural que envolve as reflexões sobre o tempo.

Virginia descreve seus personagens por meio da apreensão de seus diálogos internos, do "stream of consciousness" (fluxo de consciência), conceito introduzido pelo filósofo americano William James 
(1842-1910) em The principles of psychology (1890)14. Desaparecem em Mrs. Dalloway a perspectiva panorâmica, a presença onisciente do narrador. Não há mais uma realidade, mas diferentes perspectivas. Os pensamentos num fluxo contínuo vão e voltam, são amalgamados com estímulos sensoriais que se apresentam e são descritos numa instância por vezes desordenada, fragmentada, impressionista.

Sobre esse movimento de livre associação de ideias pré-verbal, James afirma que os termos rio ou fluxo são as metáforas que melhor descrevem esse diálogo interno. Salienta que esse monólogo interior é totalmente diferente do solilóquio, pois neste último o pensamento é descrito de forma ordenada, sendo um recurso literário habitual. Tal forma de William James descrever a consciência antecipa em quase duas décadas o que será posteriormente desenvolvido por Husserl (1859-1938) com o método fenomenológico ${ }^{18}$.

Essa extraordinária ferramenta fenomenológica permite a Virginia descrever o mundo interno de Clarissa e as vivências psicóticas do outro personagem-chave do romance, o ex-combatente da Primeira Guerra Mundial, Septimus Warren Smith. Ambos não se conhecem, nunca se encontram, e a vida de ambos corre paralela, a mundanidade de Clarissa se contrapõe ao pathos de Septimus.

Desde a Grécia Antiga, muito se tem discutido sobre as relações entre criatividade e doença mental. Uma maior revisão sobre o assunto não é escopo deste trabalho. Cumpre, porém, ressaltar que curiosamente a maior parte dos trabalhos estuda compositores, poetas, escritores e artistas do sexo masculino ${ }^{19,20}$.

Da mesma forma, é importante notar que, embora Virginia apresentasse um quadro muito grave e de grande interesse psicopatológico ${ }^{20}$, sua doença foi principalmente abordada de maneira interpretativa. Sua bissexualidade, seu feminismo, o abuso sexual na infância que sofrera de seus meio-irmãos George e Gerald, os sentimentos de culpa em relação à morte materna, a não superação da fase edípica, a inveja peniana, foram considerados argumentos e fórmulas para explicar seus complexos estados mentais a partir de suas vivências traumáticas ${ }^{22-24}$. Não são raras as formulações de que Virginia escolheu tornar-se maníaco-depressiva como forma de sobrevivência ${ }^{23,24}$. Neste momento, cumpre lembrar as questões metodológicas levantadas por Karl Jaspers na segunda parte do primeiro volume do seu Psicopatologia geral, sobre psicologia compreensiva. Lá, discorre sobre os limites da compreensão psicológica e o que ele chamou de pseudocompreensão psicológica ${ }^{15}$. Quando falha nossa capacidade de compreender os motivos dos comportamentos patológicos, deve-se então explicá-los.

Apenas muito recentemente Caramagno 22 descreveu com detalhes uma impressionante análise da frequência de transtornos de humor na família de Virginia. Seu avô, pai, mãe, irmã (a pintora Vanessa Bell), irmão (Thoby), primo e sobrinho apresentavam diferentes quadros dentro do espectro bipolar, incluindo depressões recorrentes, ciclotimia e manias francas ${ }^{20}$, o que aponta para a explicação baseada na predisposição de natureza hereditária.

Mas mesmo quando se explicam seus problemas mentais, ainda assim não se reduz a grandeza da sua humanidade. Retornando à questão da criatividade, foi espantosa a capacidade de Virginia em não apenas se lembrar de seus episódios psicóticos, mas de transformar suas vivências em matéria-prima para literatura ${ }^{20,21}$.

Para tornar Septimus mais simpático ao público, Virginia coloca que ele enlouqueceu por um choque emocional na Primeira Guerra Mundial. A guerra havia acabado há pouco e essa Inglaterra entre as duas guerras ainda tinha muito marcada a lembrança de seus mortos. Mas não apenas por razões literárias a autora coloca a gênese da loucura de Septimus como uma resposta a um evento traumático externo. Virginia acreditava piamente na importância dos eventos vitais como causadores de suas crises 25 .

Aqui se verifica a importância da compreensão de um paciente, mesmo após diagnosticado e explicado corretamente o seu problema. Cada paciente é único na maneira de reagir à sua doença e na maneira de concebê-la e no uso que fará dela na sua vida. Vejamos como Virginia elaborou os seus problemas 25 .

Sua primeira crise ocorreu após a morte da mãe, Julia, em 1895, aos 13 anos.
Em "O velho grupo de Bloomsbury" publicado em Momentos da vida ${ }^{26}$, descreve sua segunda crise em 1904 como decorrente das importantes perdas familiares que sofreu na casa onde nasceu:

"Ali nós quatro nascemos; ali minha avó morreu; ali minha mãe morreu; ali meu pai morreu; ali Stella ficou noiva de Jack Hills... após três meses de casamento ela também morreu... Quando eu me recuperei da doença, que foi naturalmente, o resultado de todas essas emoções..."

Embora a maior parte dos psiquiatras (alienista era o termo mais usado na época) consultados tenha feito adequadamente o diagnóstico de doença maníaco-depressiva, a única orientação possível era afastar-se ao máximo da vida agitada de Londres $^{27}$.

A última crise de Virginia antes do suicídio foi precedida de uma situação existencial extrema.

Principalmente no sul da Inglaterra, bombardeada continuamente, temia-se uma invasão alemã. Desde maio e junho de 1940, o casal discutia com amigos o que fariam se essa ameaça se concretizasse.

No segundo volume de sua autobiografia ${ }^{5}$, Leonard Woolf, judeu, sabia o que o esperava e à sua mulher: "Nós concordamos que se isso ocorrer nós fecharemos a porta da garagem e nos mataremos". O irmão de Virginia, Adrian Stephen, psicanalista, já havia provido o casal de doses letais de morfina para usar caso ocorresse a invasão alemã. Os Woolf consideravam que a capitulação significaria a morte para todos os judeus e sabiam que ambos estavam na lista negra da Gestapo para imediata prisão ${ }^{28}$.

Virginia mostra em Septimus todos os sintomas de um quadro maníaco psicótico. Os pensamentos de Septimus são grandiosos a respeito de si mesmo, o maior homem da humanidade, o responsável pela fundação de uma nova religião que iria renovar a sociedade, devendo trazer "a maior mensagem do mundo". Apresentando sintomas delirantes persecutórios e de autorreferência, podia ver o pensamento das pessoas e as mentiras que levantavam sobre ele, seus gestos e rostos zombeteiros. Ele apresentava alucinações visuais em que via a face de uma velha mulher entre as flores e cães se transformando em homens.

Em 1904, Virginia descreve ter escutado os pássaros cantando em grego pedindo-lhe que fizesse loucuras, enquanto o rei Eduardo lhe dirigia palavras obscenas entre as flores. Os pássaros de Septimus também lhe falarão em grego 20 anos depois.

Tal qual Virginia, Septimus recebe a orientação de repouso na cama, repouso e solidão, outras vezes os médicos lhe dizem que deveria distrair-se. A imagem que Virginia oferece dos psiquiatras não era nada elogiosa. Eram famosos, vaidosos e autoritários, cobravam muito caro e tinham pouco a oferecer, além de recomendar repouso e internação ${ }^{27}$.

Sir George Savage, Sir Maurice Craig, Theophilus Hyslop (todos do Bethlem Hospital) e uma das pioneiras entre as mulheres a exercer a psiquiatra, Octavia Wilberforce, foram várias vezes, e em épocas diferentes, consultados pelos Woolf durante as crises, e principalmente por Le-onard, que temia ter filhos, numa época em que as teorias de degeneração e eugenia eram comuns ${ }^{27}$.

Tal qual Virginia, Septimus ouvira de seu médico a mesma recomendação de repousar, sem visitas e sem livros, seis meses de repouso "até que um homem que nos chega com cinquenta quilos saia pesando oitenta".

"Os homens não devem cortar as árvores. Há um Deus (anotava tais revelações nas costas de envelopes). Mudar o mundo. Ninguém mata por ódio... Um pardal, pousado na grade em frente piou 'Septimus, Septimus', quatro ou cinco vezes, e, cascateando as suas notas, continuou a cantar alto, com frescor, em palavras gregas, que o crime não existe, e, tendo chegado outro pardal, cantavam ambos, com voz prolongada e penetrante, em grego...

A gaveta da mesa estava cheia daqueles escritos; sobre a guerra; sobre Shakespeare; sobre grandes descobertas; sobre a inexistência da morte. Ultimamente, excitara-se de súbito, sem motivo algum... e agitara as mãos, gritando que conhecia a verdade. Que conhecia tudo! Aquele homem, o amigo morto, Evans, tinha voltado, dizia. Estava cantando por detrás do biombo. Ela escrevia o que ele falava. Algumas coisas eram muito bonitas; outras, verdadeiras tolices. 
E sempre parava no meio e mudava de ideia; desejava acrescentar algo; ouvia algo novo; escutava com a mão no ouvido"7.

Septimus Warren Smith comete suicídio atirando-se da janela de sua casa da mesma forma como Virginia o fizera sem sucesso alguns anos antes.

\section{Conclusão}

A relação entre criatividade e doença mental, particularmente transtorno bipolar do humor, é bastante explorada na literatura psiquiátrica, de forma sistemática, há pouco mais de 20 anos $^{29}$.

A criatividade como traço genético e facilitador da concepção artística em pacientes bipolares encontra em Virginia Woolf um de seus exemplos mais emblemáticos.

Em vários de seus escritos, mas em particular no romance Miss Dalloway, aqui abordado, Virginia recria em seu personagem Septimus alterações psicopatológicas que a própria autora vivenciara em suas fases da doença bipolar.

A possibilidade de transformar momentos de profundo sofrimento psíquico e de graves alterações psicopatológicas de Virginia Woolf em arte faz de seu Miss Dalloway uma das mais importantes páginas literárias dessa relação instigante

\section{Referências}

1. Zschirnt C. Libros: todo lo que hay que leer. Madrid: Taurus Ediciones; 2004.

2. Lehmann J. Virginia Woolf. Rio de Janeiro: Jorge Zahar Editora; 1989.

3. Woolf V. O quarto de Jacob. São Paulo: Novo Século Editora, 2008.

4. Figueroa CV. Virginia Woolf: enfermedad mental y creatividad artística. Rev Méd Chile. 2005;133:1381-8.

5. Woolf L. Journey not the arrival matters: an autobiography of the years 1939 to 1969. Washington: Harvest Book; 1989.

6. Cunningham M. As horas. São Paulo: Companhia das Letras; 1998.

7. Woolf V. Mrs Dalloway. Rio de Janeiro: Nova Fronteira; 1980.
8. Bloom H. Gênio: os cem autores mais criativos da história da literatura. Rio de Janeiro: Objetiva; 2002.

9. De la Fuente I. "A mi tía Virginia Woolf la llamábamos señora Dalloway" [entrevista com Virginia Nicholson]. El Pais. 2008.

10. Woolf V. A room of one's own. Orlando: Hartcourt Books; 2005.

11. Mumford L. Technics \& civilization. New York: Harvest Books; 1963.

12. Santo Agostinho. Confissões. São Paulo: Paulus; 1984.

13. Gilles MA. Henry Bergson and British modernism. New York: McGill-Queen's Press; 1996.

14. Nobre de Melo AL. Psiquiatria. Rio de Janeiro: Civilização Brasileira; 1979.

15. Jaspers K. Psicopatologia geral. São Paulo: Atheneu; 1973.

16. Dalgalarrondo P. Notas sobre uma psicopatologia a partir do pensamento de Henri Bergson. Psiquiatr Biol. 1994;2(3):77-80.

17. Kumar S. Virginia Woolf and Bergson's duree. New York: Folcroft Editions; 1977.

18. Herzog M. William James and the development of phenomenological psychology. Europe. History Human Sci. 1995;8(1):29-46.

19. Goodwin FK, Jamison KR. Manic-depressive illness: bipolar disorders and recurrent depression. New York: Oxford University Press; 2007.

20. Jamison KR. Touched with fire: Manic-depressive illness and the artistic temperament. New York: Free Press; 1993.

21. Dalsimer K. Virginia Woolf (1882-1941). Am J Psychiatry. 2004;16(5):809.

22. Caramagno T. The flight of the mind: Virginia Woolf's art and manic depressive illness. Berkeley: University of California Press; 2005.

23. Gruber R. Will to create a woman. New York: Basic Books; 2005.

24. Szasz T. My madness saved me: the madness and marriage of Virginia Woolf. New York: Transaction Publishers, 2006.

25. Gordon C, Pryor R, Watkins G. Sounds from the bell jar: ten psychotic authors. Cambridge: Maior Books; 1998.

26. Woolf V. Momentos da vida. Rio de Janeiro: Nova Fronteira; 1986.

27. Trombley S. All that summer she was mad, Virginia Woolf and her doctors. London: Junction Books; 1981.

28. Briggs J. Virginia Woolf: an inner life. London: Penguin Books; 2005.

29. Andreasen NC. Creativity and mental illness: prevalence rates in writers and their first-degree relatives. Am J Psychiatry. 1987:144:1288-92. 